Iranian Journal of Breast Diseases. 2020; 13(2):28-36.

\section{Original Article \\ Factors Affecting Breast Self-examination Behavior in Housewives in Birjand Based on the Transtheoretical Model}

\author{
Miri $\mathbf{M}^{1 *}$, Moodi $\mathbf{M}^{2}$, Miri $\mathbf{M R}^{2}$, Sharifzadeh $\mathbf{G h}^{3}$, Norozi $\mathbf{E}^{2}$ \\ ${ }^{1}$ Social Determinants of Health Research Center, Birjand University of Medical \\ Sciences, Birjand, Iran \\ ${ }^{2}$ Department of Health Education and Promotion, Social Determinants of Health \\ Research Center, Faculty of Health, Birjand University of Medical Sciences, \\ Birjand, Iran \\ ${ }^{3}$ Department of Epidemiology, Social Determinants of Health Research Center, \\ Faculty of Health, Birjand University of Medical Sciences, Birjand, Iran
}

Receive: $5 / 5 / 2020$ Accepted: $15 / 7 / 2020$

${ }^{*}$ Corresponding Author: mmiri1062@gmail.com

Ethics Approval: Ir.bums.1395.51

\begin{abstract}
Introduction: Breast self-examination is a simple, inexpensive, and technology-free tool for early detection of breast cancer, and in most countries, specifically in developing countries, it is the only genuine way to detect breast cancer rapidly. So, the current study was done to determine the factors affecting breast self-examination behavior in housewives.
\end{abstract}

Methods: This descriptive-analytical study was done with 450 housewives aged 20-40 years visiting health centers in Birjand, South Khorasan. The sample was randomly selected using a multistage cluster sampling method. Data were collected through a researcher-made questionnaire consisting of demographic information and transtheoretical model constructs and then were entered into the SPSS 19 software. Variables of normal distribution were analyzed using $t$ tests and one-way analysis of variance, while nonnormal data were analyzed using the Kruskal-Wallis, Mann-Whitney, and Fisher's exact tests.

Results: The mean age of women was $30.7 \pm 5.2$ years. Based on the structure of the change steps, $32.9 \%$ of the women were at the precontemplation stage, $19.6 \%$ at the contemplation stage, $23.3 \%$ at the preparation stage, $18.2 \%$ at the action stage, and $6 \%$ at the maintenance stage. The mean score was $2.33 \pm 0.57$ for the decision structure, $2.51 \pm 0.82$ for the change process, and $1.61 \pm 0.81$ for the self-efficacy. Among the variables studied, the level of education and awareness showed a significant relationship with the model constructs $(\mathrm{p}<0.05)$.

Conclusion: According to the results of the study, most women studied did not perform breast self-examination. Consequently, it is necessary to perform educational interventions to improve the behavior of breast selfexamination.

Keywords: Breast Self-Examination, Transtheoretical Model, Housewives 
مقاله بِثروهشى

عوامل موثر بر انجام رفتار خودآزمايى يَتان در زنان خانهدارشهر بيرجند بر اساس الكوى فر انظرى

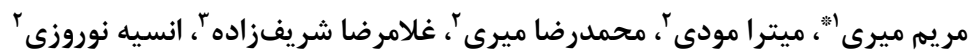
' مركز تحقيقات عوامل اجتماعى موثر بر سلامت، دانشعاه علوم يزشكى بيرجند، بيرجند، ايران

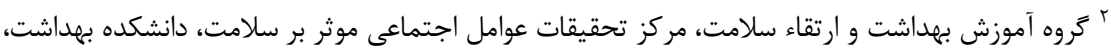
دانشعاه علوم يزشكى بير جند، بيرجند، ايران

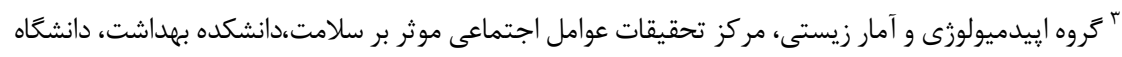
علوم يزشكى بيرجند، بيرجند، ايران
فصلنامه بيمارى هاى يستان ايران

$1 r q 9$ ! $1 \%(r):$ rq_r
OU.

مقدمه: خودآزمايى يستان ابزارى ساده، ارزان و بدون نياز به فناورى جهت تشخيص زودهنحًام

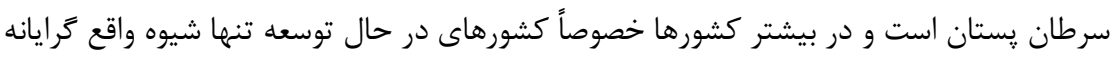

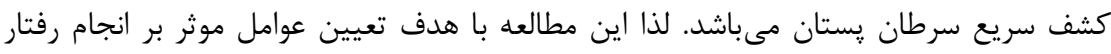

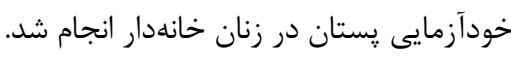

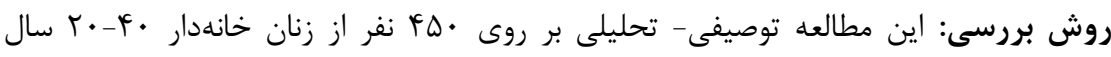

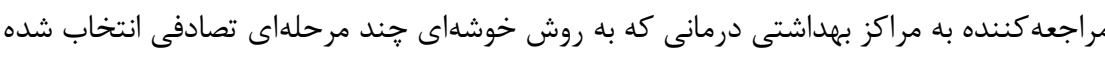

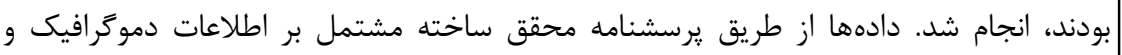

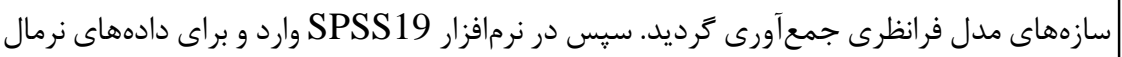

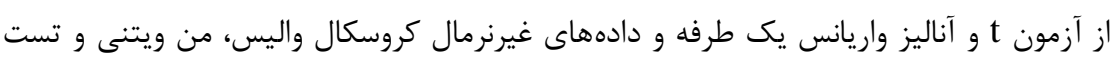
دقيق فيشر استفاده شد.

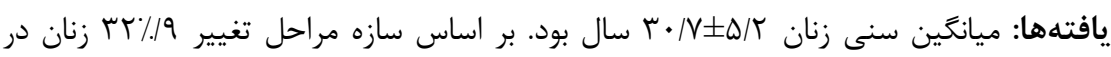

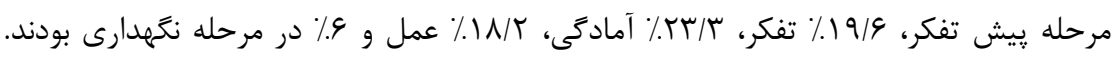

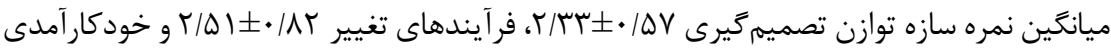

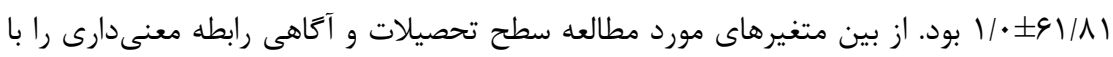

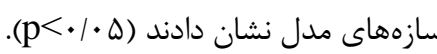
نتيجهَيرى: با توجه به نتايج مطالعه اكثريت زنان مورد مطالعه رفتار خودآزمايى يستان را انجام

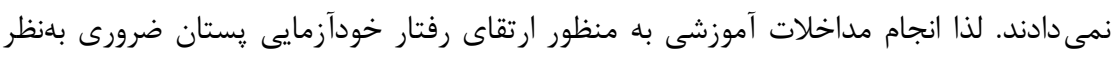
مىرسد. |وازههاى كليدى: خودآزمايى يستان، مدل فرانظرى، زنان خانهدار

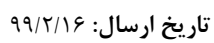
تاريخ يذيرش:

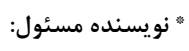
mmiri1062@gmail.com 
تاثير گذارى آموزش، به استفاده مناسب از تئورىهاى علوم

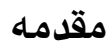

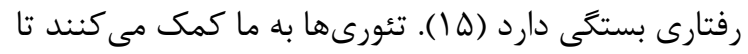

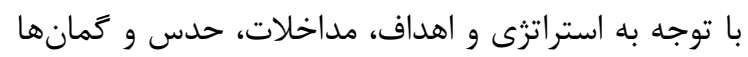

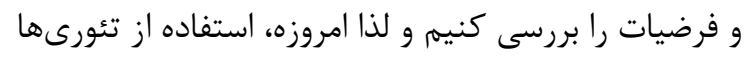

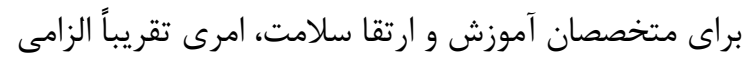

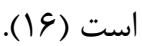

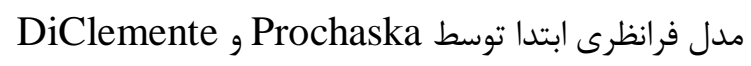

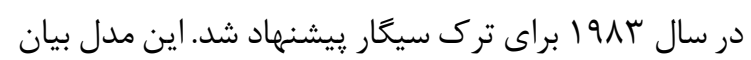

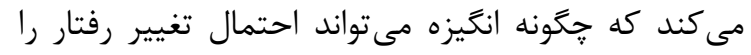

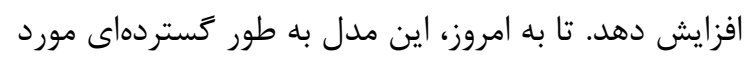

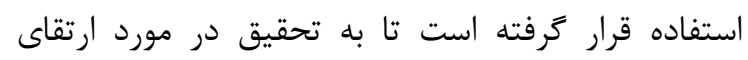

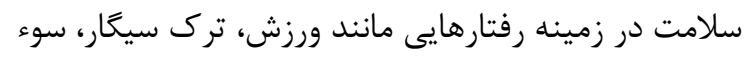
مصرف مواد و الكل، مديريت استرس، محدود كردن آفتاب، رئل

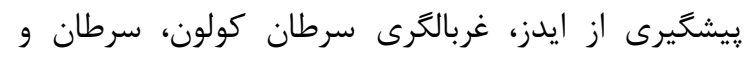
ماموكرافى كمك كند (IV) اين مدل شامل جهار سازه مراحل تغيير، فرايندهاى تغيير،

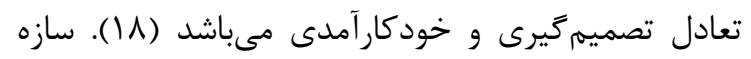

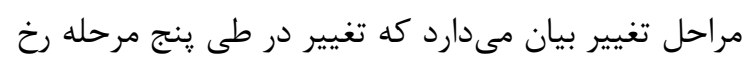

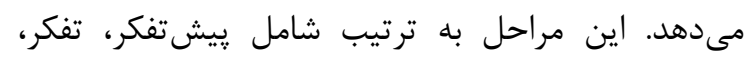

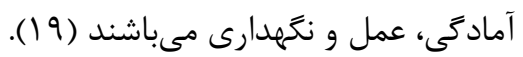
دومين سازه مدل شامل فرآيندهاى تغيير است كه شارئ فامل

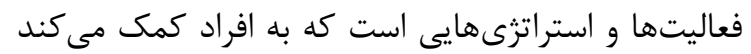

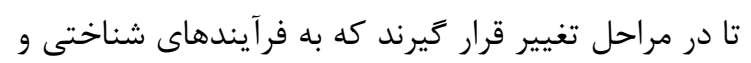
رفتارى طبقهبندى مىشود (·F). سازه ديكر اين مدل، سازه

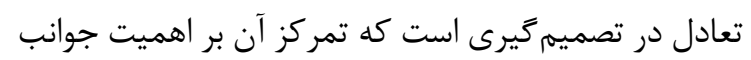

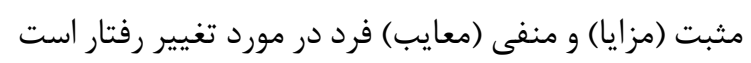

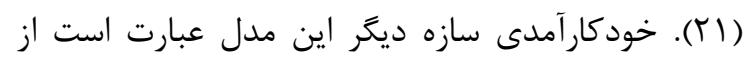

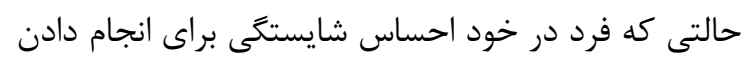
كارى با اطمينان به توانايى خود براى احسى انجام عملى دارئى دارد

با توجه به اينكه سرطان يستان به عنوان يكى از اولويتهاى

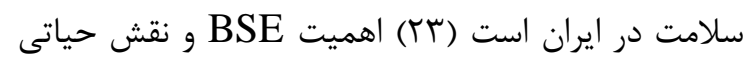

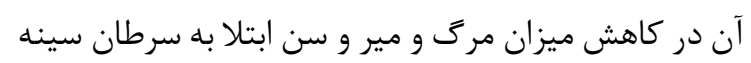

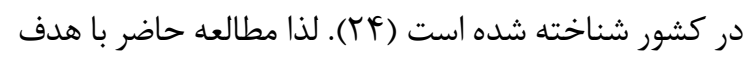

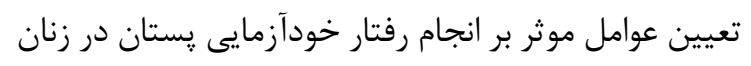

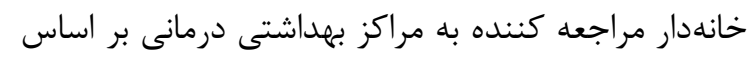
الكَوى فرانظرى طراحى و انجام شد.

سرطان يستان شايعترين سرطان و دومين علت مرك و مير

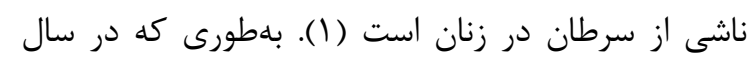

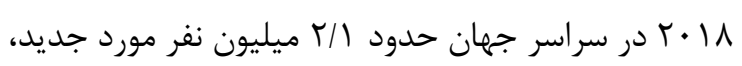

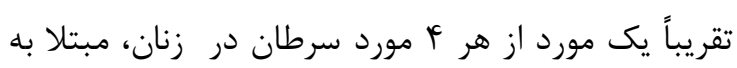

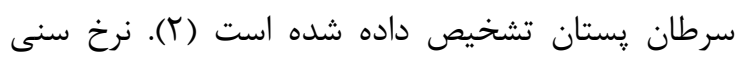

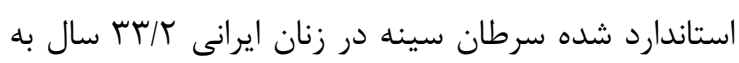

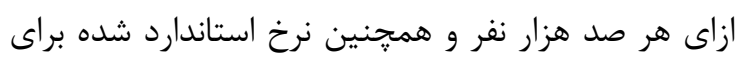

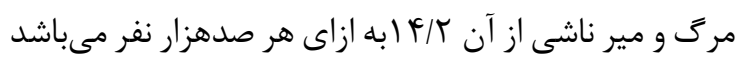

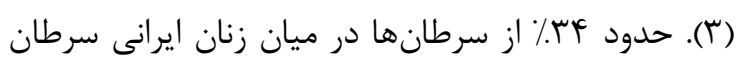

$$
\text { سينه مىباشد (Y). (Y). }
$$

تشخيص زودهنحام سرطان سينه در زنان موجب افزايش (؟).

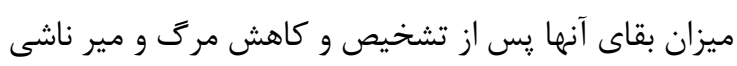

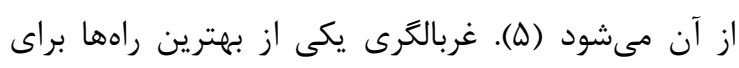

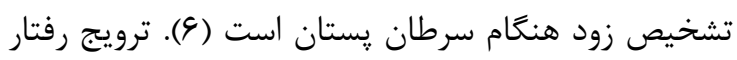

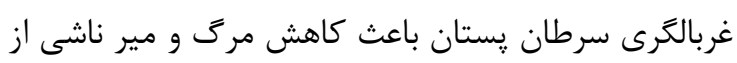

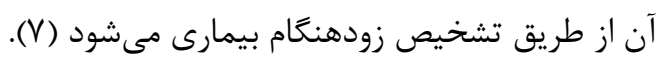

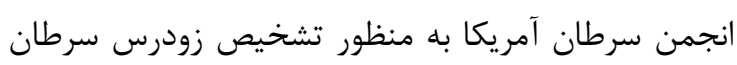

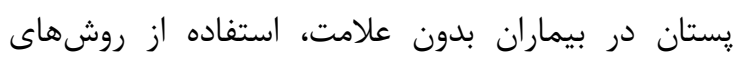

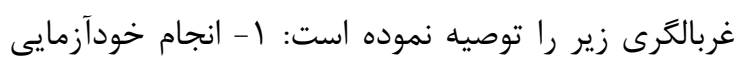

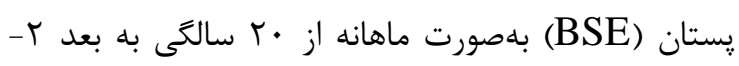

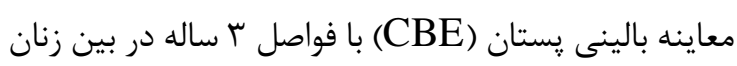

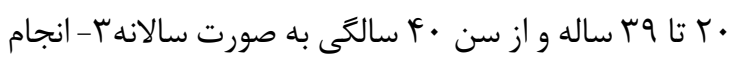

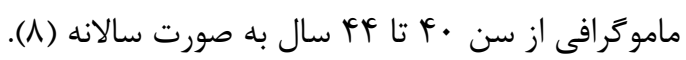
BSE

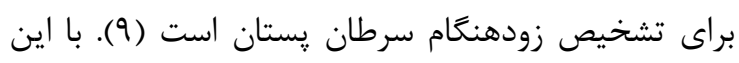

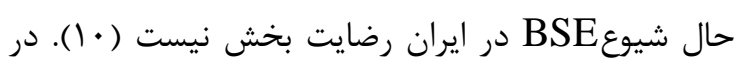

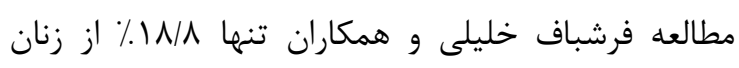
را انجام مى مادند (11) BSE

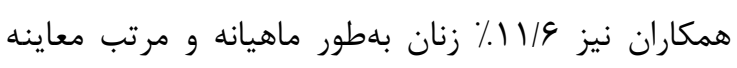

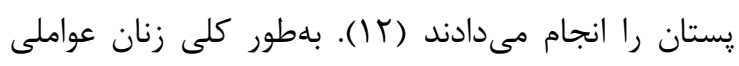

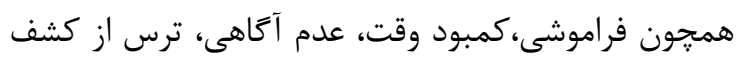

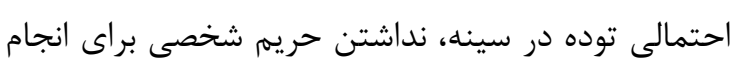

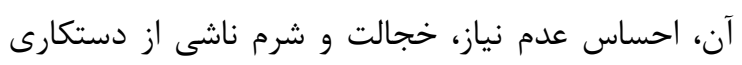

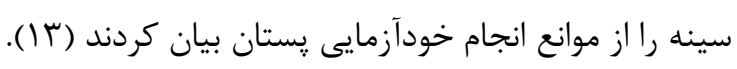

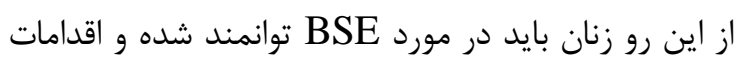

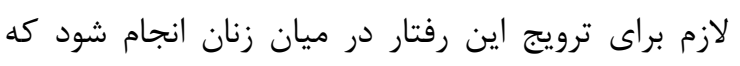

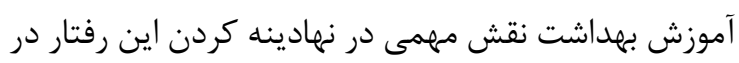
ميان زنان در جامعه ايفا مى كند (f) (I). 
كزارش شد كه حداقل نمره كسب شده 11 و حداكثر •9

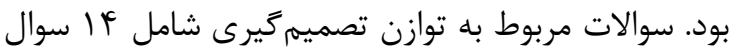

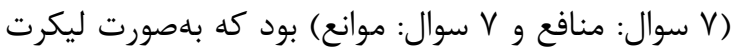

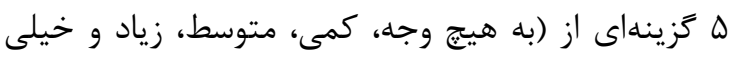

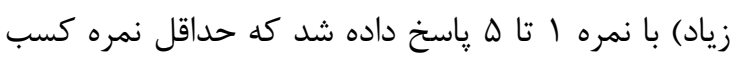

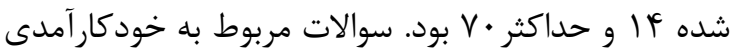

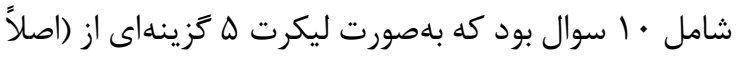

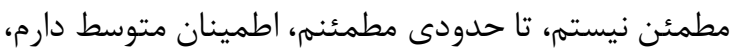

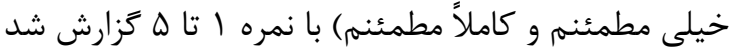
كه حداقل نمره كسب شده • ا و حداكثر •ه بود. سوالات

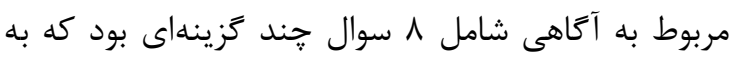

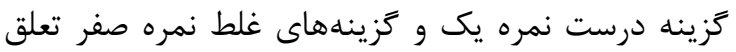
كرفت كه دامنه نمرات بين • تا م بود.

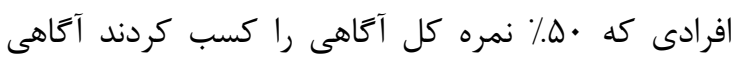

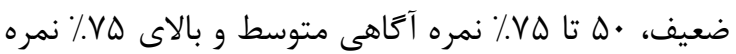
را كسب نمودند از آكاهى خوب برخوردار بودند. يرسشنامهها بلهورت خود ايفا توسط زنان شركت كننده در مطالعه

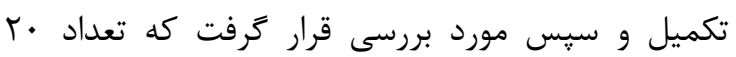
يرسشنامه بهدليل ناقص بودن از مطالعه حذف كرديد. تجزيه و تحليل دادهها با استفاده از نرمافزار

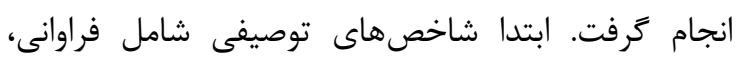
ميانگين و انحراف معيار گزارش شد و در سازه مراحل تغيير

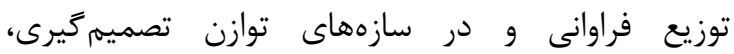

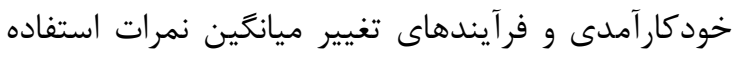

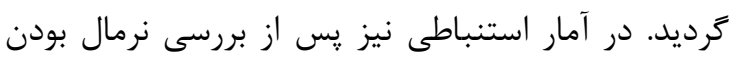

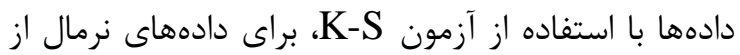

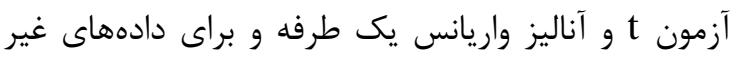

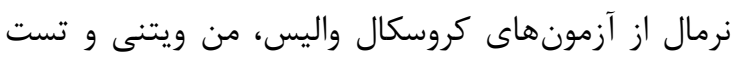

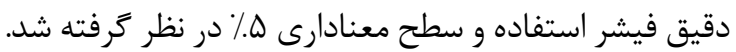

\section{صافته هـا}

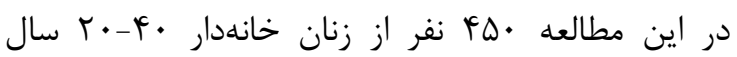
مراجعه كننده به مراكز بهداشتى درمانى شهر بيرجند مورد إندان

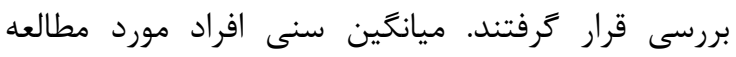

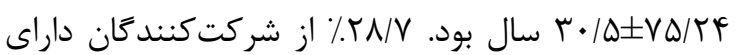
سطح تحصيلات دييلم و 9V/^٪ از زنان متاهل بودند (جدول شماره|). بر اساس مراحل تغيير انجام رفتار

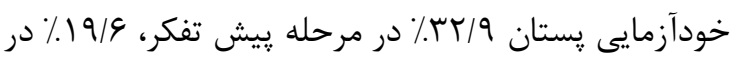

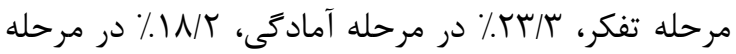

\section{مواد و روشها}

اين مطالعه توصيفى تحليلى بر روى • لهأ نفر از زنان خانهدار

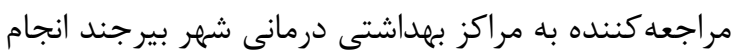

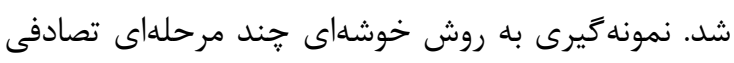

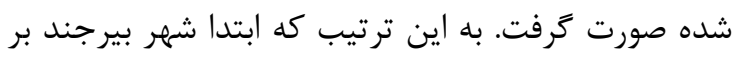

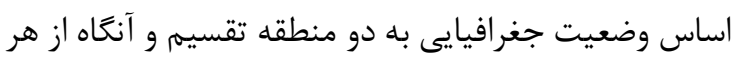

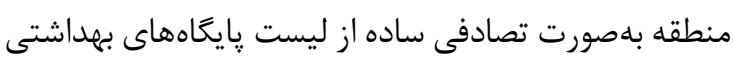

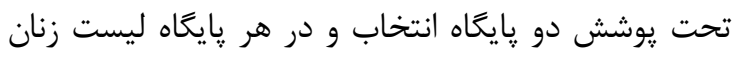

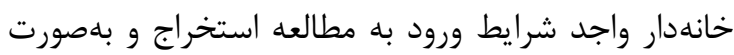
تصادفى ساده از هر ليست •و نفر انتخاب كرديد.

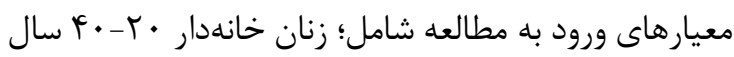
مر اجعه كننده به مراكز بهداشتى درمانى بدون سابقه سرطان

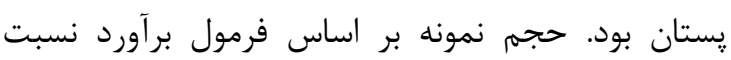
خو

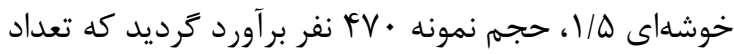

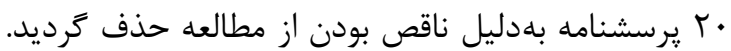

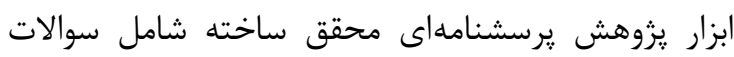

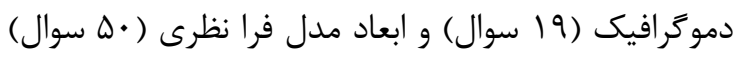

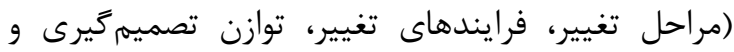

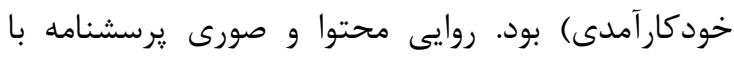

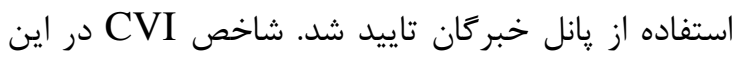

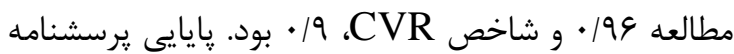

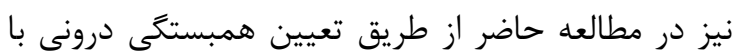
روش محاسبه ضريب آلفاى كرونباخ مورد بررسى قرار تر مرفت كه آلفاى كرونباخ براى سازه توازن تصميمكيرى ل/VF•،

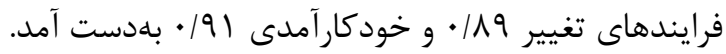

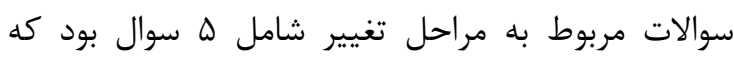

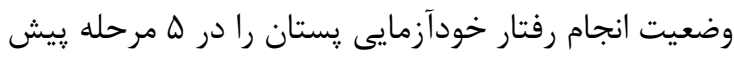

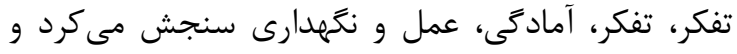

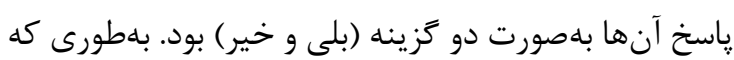

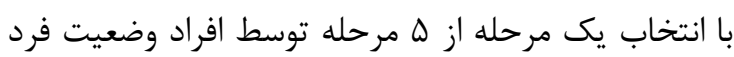

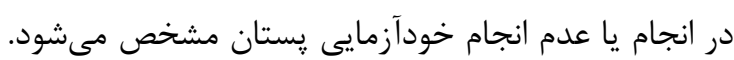

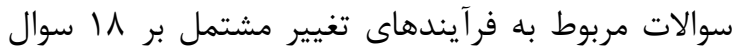

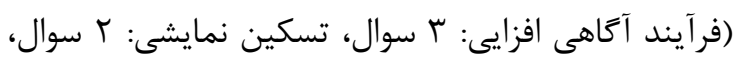

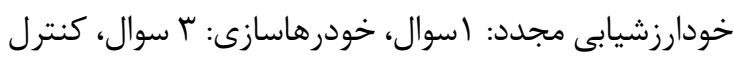
محرك: r سوال، ارزيابى مجدد محيط: r سوال، روابط البط

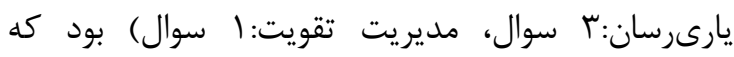

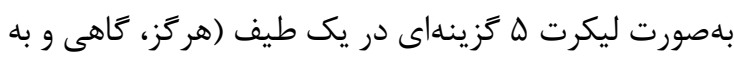

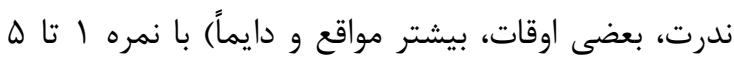


مورد مطالعه سطح تحصيلات و آكاهى با سازه مراحل تغيير رابطه معنى دارى را نشان دادند (جدول

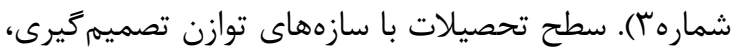

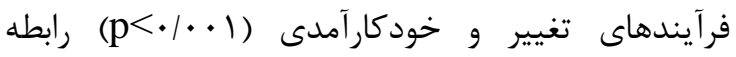
معنى دارى را نشان داد اما متغيرهاى سن و وضعيت تاهل رابطه معنى دارى با سازههاى مدل نداشتند (جدول ؟F).
عمل و \&\% در مرحله نتخهدارى بودند (جدول شمارهץ).

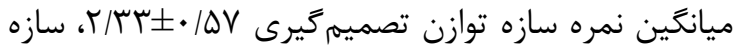

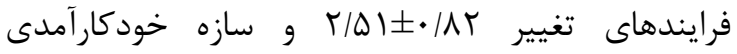

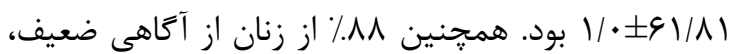

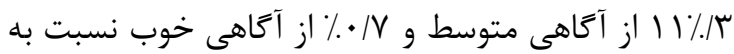

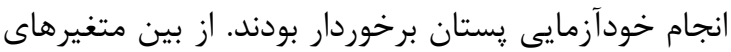

جدول ا: توزيع فراوانى متغير هاى جمعيتشناختى در زنان مورد مطالعه

\begin{tabular}{|c|c|c|c|}
\hline درصد & فراوانى & & متغير \\
\hline $4 q / 1$ & TYI & زير •r سال & \\
\hline$\Delta \cdot / 9$ & rtq & بالاى •r سال & كروه سنى \\
\hline$r \Delta / \Lambda$ & 119 & ابتدايى & \\
\hline$I V / T$ & $\vee \wedge$ & راهنمايى و دبيرستان & \\
\hline TA/V & $1 r 9$ & دييلم & سطح تحصيلات \\
\hline$\wedge$ & re & فوق دييلم & \\
\hline$r \cdot / r$ & 91 & ليسانس و بالاتر & \\
\hline $9 \vee / \Lambda$ & fF. & متاهل & وضعيت تاها \\
\hline$T / T$ & $1 \cdot$ & 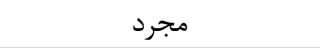 & وصعيت نهل \\
\hline$r T / Q$ & 1re & ا فرزند & \\
\hline$r \varepsilon / F$ & IDT & ك ا برزند & \\
\hline 1910 & 99 & ب ا فرزند & تعداد فرزندان \\
\hline $1 \cdot / r$ & fr & 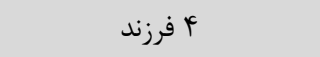 & \\
\hline$k / \mu$ & 11 & ه فرزند و بيشتر & \\
\hline $1 \cdot 10$ & FV & 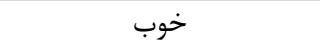 & \multirow{4}{*}{ ارزيابى از وضعيت در آمد خانوار } \\
\hline$q 4 / \Gamma$ & rیs & 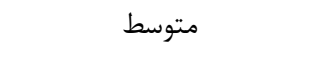 & \\
\hline$r \Delta / r$ & $11 r$ & ضعيف & \\
\hline $1 \cdots$ & FED & 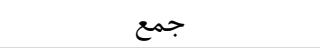 & \\
\hline $9 / 1$ & (1) & بلى و مراجعه به يزشك & \multirow{3}{*}{ سابقه ابتلا به ناراحتى يستان در فرد } \\
\hline$\Delta / \Gamma$ & rF & بلى و بدون مراجعه به يزشك & \\
\hline$\Lambda \bowtie / \varphi$ & rAd & خير و بدون ناراحتى & \\
\hline$r / r$ & 19 & 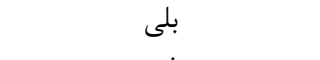 & \multirow{2}{*}{ سابقه ابتلا به سرطان يستان در بستكًان درجه يكى } \\
\hline $9 \Delta / \wedge$ & Ft & 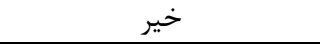 & \\
\hline
\end{tabular}

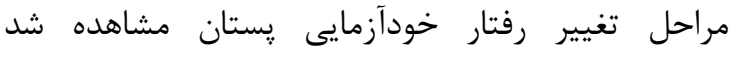

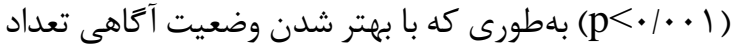
بيشترى از افراد مورد مطالعه در مرحله عمل و نخَهدارى بـى

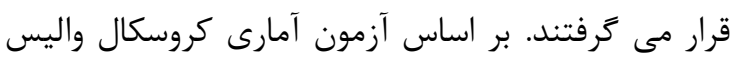
تفاوت معنادارى بين ميانگين نمره سازه توازن تصميمى ميرى

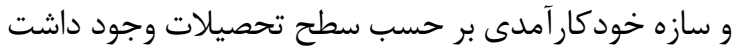
بهطورى كه با بالا رفتن سطح تحصيلات ميانگين نمره سازه

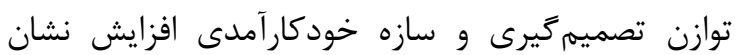

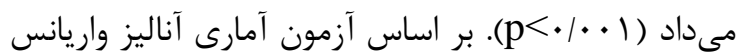
يك طرفه تفاوت معنادارى بين ميانگين نمره سازه فرايندهاى تغيير بر حسب سطح تحصيلات وجود داشت بهطورى كه با بالا رفتن سطح تحصيلات ميانگين نمره سازه
بر اساس يافتههاى اين جدول مشخص مىشود كه بيشتر

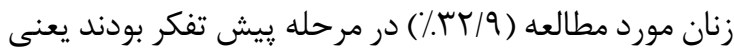
تاكنون خودآزمايى يستان را انجام نداده و قصدى هم براى

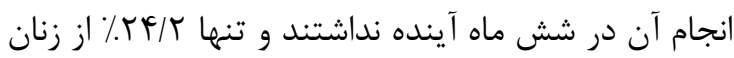

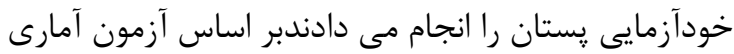
تست دقيق فيشر رابطه معنادارى بين سطح تحصيلات با

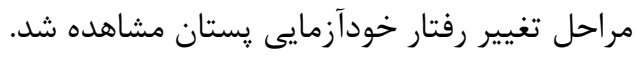
بهطورى كه با بالا رفتن سطح تحصيلات تعداد بيشترى از افراد مورد مطالعه در مرحله عمل و نكَهدارى قرار مى گرفتند

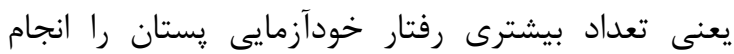

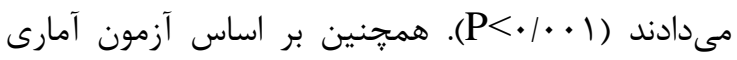
تست دقيق فيشر رابطه معنادارى بين وضعيت آكاهى با 


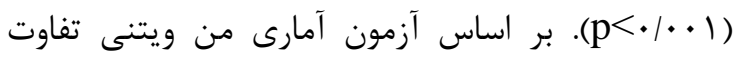
معنادارى بين ميانگين نمره سازههاى مدل فرانظرى بر حسب گروههاى سنى و وضعيت تاهل وجود نداشت ميت مئ $\cdot(\mathrm{p}>\cdot / \cdot \Delta)$

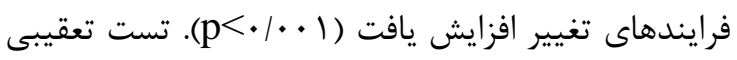
توكى نشان داد بين ميانخين نمره سازه فرايندهاى تغيير در

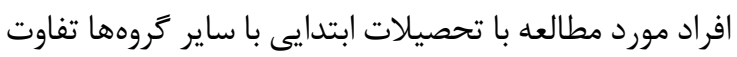

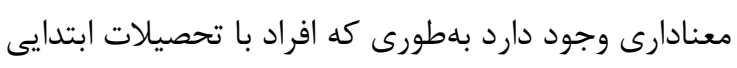

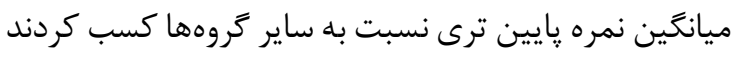

جدول r: توزيع فراوانى مراحل تغيير انجام خودآزمايى پِيسان در زنان مورد مطالعه

\begin{tabular}{|c|c|c|}
\hline درصد & 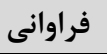 & مراحل تغيير \\
\hline rT/Q & $14 \lambda$ & يِيش تفكر (تاكنون خودآزمايى يستان انجام ندادهام و قصدى هم براى انجام آن در شش ماه آينده ندارم) \\
\hline $19 / 9$ & 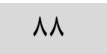 & تفكر (تاكنون خودآزمايى پِتان انجام ندادهام ولى قصد دارم در طى شش ماه آينده آن را انجام دهم) \\
\hline$r$ r & $1 \cdot 0$ & آمادگى (تاكنون خودآزمايى پستان انجام ندادهام ولى قصد دارم در طى يك ماه آينده آن را انجام دهم) \\
\hline $1 \mathrm{~N} / \mathrm{T}$ & NT & هم عمل (كمتر آن شش ما بهطور منظم انجام دهم) كه خودآزمايى پِتان را به صورت ماهيانه انجام مىدهم و قصد دارم در طى سال آينده \\
\hline 9 & TV & آينَهدارى (بيشتر از شم آن را انجام دهم) \\
\hline $1 \cdots$ & $F \Delta \cdot$ & جمع \\
\hline
\end{tabular}

جدول با: مقايسه توزيع فراوانى سازه مراحل تغيير بر حسب متغيرهاى مورد مطالعه

\begin{tabular}{|c|c|c|c|c|c|c|c|}
\hline 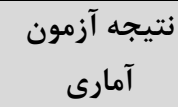 & نغگهدارى & 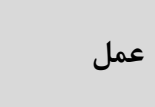 & آمادَى & تفكر & بيش بيشكر & & متغي \\
\hline \multirow{4}{*}{$\begin{array}{c}X 2 r \vee / \wedge \Delta= \\
\mathrm{df}=\mid r \\
\mathrm{P}<\cdot / \cdot \cdot 1\end{array}$} & $(1 \% / N) T$ & $(\mid f \% / V) \mid V$ & $(r \cdot \% / r) r \Delta$ & $(1 \cdot \% / / T) \mid r$ & ( & ابتدايى & \multirow{4}{*}{ سطح تحصيلات } \\
\hline & $(\varphi \% / / 4) \Delta$ & $(19 \% / / T) 10$ & $(\mid F \% / / 1) \backslash 1$ & $(T \Lambda \% / T) T r$ & (rT\%/lI rd & ربيرستان & \\
\hline & $(9 \% / r) \mid r$ & $(I V \% / I) T T$ & (4T\%/D) rq & $(19 \% / / F) r \Delta$ & $(\Psi) \% \mid \Lambda) \& \mid$ & دييلم & \\
\hline & $(\xi \% / / \Gamma) \wedge$ & $(T r \%)$ TA & (rT\% & $(r r \% / \Lambda) Y q$ & $(T \Delta \% / r) r T$ & تحصيلات دانشَاهى & \\
\hline \multirow{3}{*}{$\begin{array}{c}X 2 r \downarrow / 9 \Lambda= \\
d f=\wedge \\
p<\cdot / \cdot \cdot ।\end{array}$} & $(\Delta \% / /)$ r. & $(1 F \% / q) \Delta q$ & $(Y F \% / V) 9 \wedge$ & $(r \cdot \% / V) \wedge r$ & $(r F \% / . \mid \varphi) \mid r v$ & ضعيف & \multirow{3}{*}{ وضعيت آكاهى } \\
\hline & $(11 \% / 1 \Lambda)^{9}$ & ( & $(I r \% / V) V$ & $(१ \% / \wedge) \Delta$ & $(r) \% / \varepsilon) 11$ & متوسط & \\
\hline & ו (ז/./ז) & 1 & - & 1 & - & خوب & \\
\hline
\end{tabular}

جدول f: مقايسه ميانغَين نمره سازههاى مدل بر حسب متغيرهاى دموكرافيك تصان.

\begin{tabular}{|c|c|c|c|c|c|c|c|}
\hline \multicolumn{2}{|c|}{$\begin{array}{l}\text { سازه فر آيندهاى تغيير } \\
\text { M } 1 \text { SD }\end{array}$} & \multicolumn{2}{|c|}{$\begin{array}{c}\text { سازه خود كار آمدى } \\
\text { M土SD }\end{array}$} & \multicolumn{2}{|c|}{$\begin{array}{c}\text { سازه توازن تصميم } \text { Mيرى } \\
M \pm S D\end{array}$} & \multicolumn{2}{|c|}{ سازه مدل متغير } \\
\hline \multirow{5}{*}{$\begin{array}{l}\mathrm{F}=11 / 1 \mathrm{~V} \\
\mathrm{p}<\cdot / \cdot \bullet\end{array}$} & $r / l / \cdot \pm / \Lambda r$ & \multirow{5}{*}{$\begin{array}{l}\mathrm{F}=r \varepsilon / r . \\
\mathrm{p}<\cdot / \cdot \cdot 1\end{array}$} & $1 / \cdot \pm r r / \Delta q$ & \multirow{5}{*}{$\begin{array}{l}\mathrm{F}=\Lambda \Lambda / F r \\
\mathrm{p}<\cdot / \cdots 1\end{array}$} & $r / \cdot r \cdot \pm|q|$ & ابتدايى & \multirow{5}{*}{ سطح تحصيلات } \\
\hline & $r|\Delta| \cdot \pm|\Lambda|$ & & 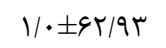 & & $r / \cdot \pm r \varepsilon / \Delta q$ & راهنمايى و متوسطه & \\
\hline & $r / \cdot \pm q 9 / V V$ & & $1 / \cdot \pm V \Psi / \wedge \varepsilon$ & & $r / \cdot \pm F \Delta / F V$ & دييلم & \\
\hline & $r / \cdot \pm \Lambda F / V \Delta$ & & $1 / \cdot \pm q r / \wedge \Delta$ & & $r / \cdot \pm \Delta \Delta / \kappa_{\Lambda}$ & فوق دييلم & \\
\hline & $T / \cdot \pm G T / V G$ & & $1 / \cdot \pm \varepsilon N / \Lambda)$ & & $r / \cdot \pm r \varepsilon / \Delta F$ & ليسانس و بالاتر & \\
\hline \multirow{2}{*}{$\begin{array}{l}\mathrm{t}=-\cdot \mid \Lambda \mathrm{r} \\
\mathrm{P}=\cdot|\boldsymbol{\psi}|\end{array}$} & $r / \mathcal{F} \Lambda \pm \cdot|\Lambda|$ & $Z=-\cdot / \Lambda \Lambda$ & $1 / \cdot \pm \Delta \& / V \varepsilon$ & $Z=1 / \cdot r$ & $r / T V \pm \cdot / 9$ & زير •r سال & \multirow{2}{*}{ كروه سنى } \\
\hline & $r / \Delta F \pm \cdot / \Lambda F$ & $\mathrm{P}=\cdot / \mu \wedge$ & $1 / \cdot \pm \varphi 9 / \wedge \varphi$ & $\mathrm{P}=\cdot / r$ & $T / T \pm \cdot / \Delta q$ & بالاى •r سال & \\
\hline $\mathrm{t}=-1 / 9 \Lambda$ & $r / \Delta \pm \cdot / \Lambda T$ & $Z=-r / T)$ & $1 / 9 \pm \cdot|1|$ & $\mathrm{Z}=-1 / \cdot 9$ & T/ & متاهل & \multirow{2}{*}{ وضعيت تاهل } \\
\hline$P=\cdot 1 \cdot 9$ & $r / Q Y \pm \cdot / V q$ & $\mathrm{P}=\cdot / \cdot V$ & $T / K \pi \pm \cdot / 99$ & $\mathrm{P}=\cdot / r q$ & $r / \Delta \cdot \pm / 9 \Delta$ & مجرد & \\
\hline
\end{tabular}




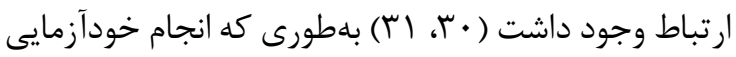

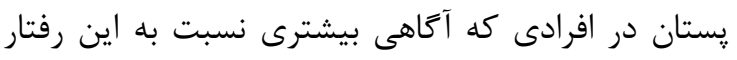

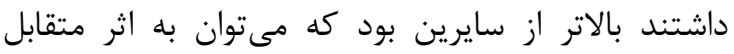
تحصيلات و آكاهى بهعنوان يكى عامل موثر اشاره كرد. با باني توجه به اينكه سطح تحصيلات نيز عاملى تاثير كذار بر انجام رفتار خودآزمايى يستان بود مى توان كفت كه افزايش سطح تحصيلات عاملى موثر در بالا رفتن سطح آكاهى افراد شده

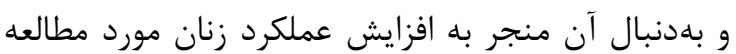
مىشود. مى توان كَفت افزايش سطح تحصيلات منجر به إنه

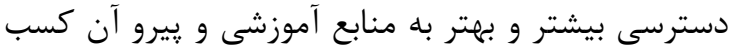

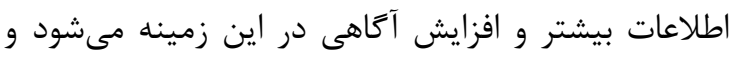
نهايتاً افزايش عملكرد را بهدنبال دارد. در مطالعه حاضر ميانكين نمرات سازههاى مدل با سطح

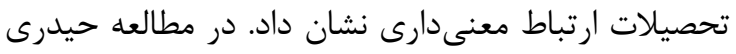

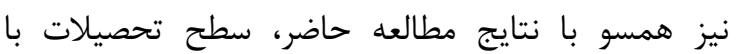

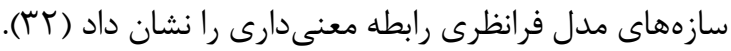
در مطالعه يِيراسته نيز با افزايش سطح تحصيلات ميانخين

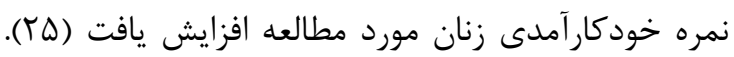
ارتباط معنىدار سازههاى مدل با سطح تحصيلات كوياى اين مطلب است كه افراد با تحصيلات بالاتر قادر هستند اطلاعات بهداشتى بيشترى را كسب نمايند و سواد سلامت

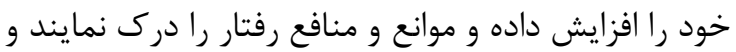
بتوانند با كسب مهارت خود كارآمدى خود را افزايش دهند.

\section{نتيجهكيرى}

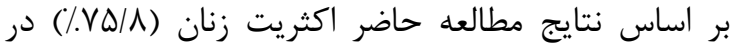
مرحله بِيش عمل (ييش تفكر + تفكر +آمادَى) قرار داشتند

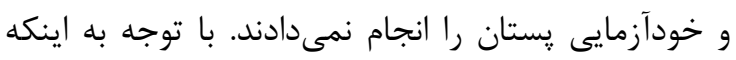
شيوع سرطان يستان در ايران در حال افزايش است و در دران مقايسه با كشورهاى پيشرفته سن ابتلا بسيار پيايينتر

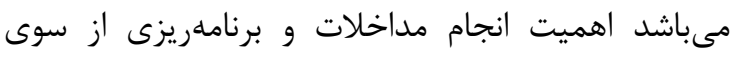

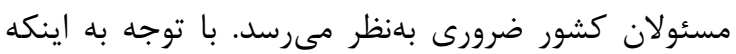

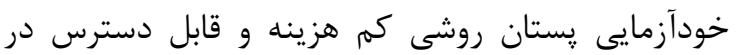

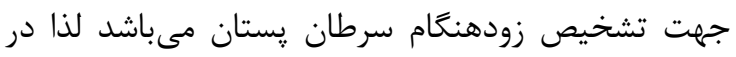

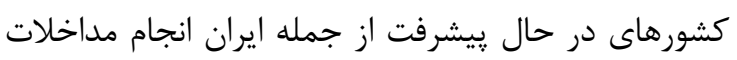

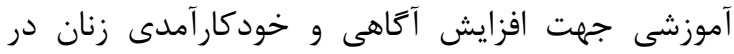
خصوص سرطان يستان و انجام خودآزمايى يستان مى تواند در كاهش اين بيمارى تاثير جشمغيرى داشته باشد. همجنين استفاده از مدل هاى آموزش بهداشت در نظاميندي

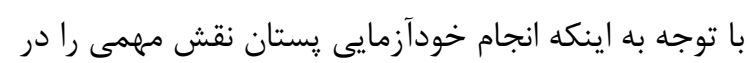

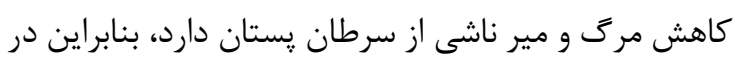

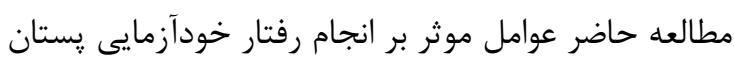
در زنان خانهدار بر اساس الكَوى فرانظرى مورد بررسى قرار إنار كرفت. بر اساس نتايج حاصل از مطالعه، اكثريت افراد داد مورد

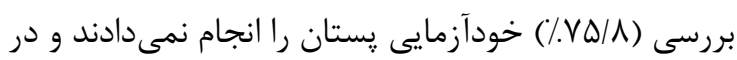

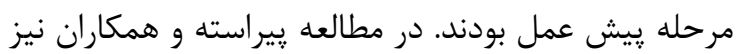

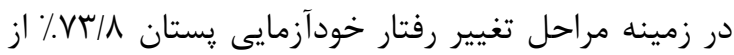

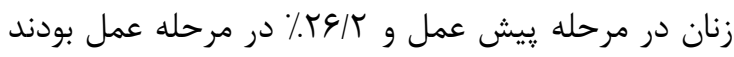

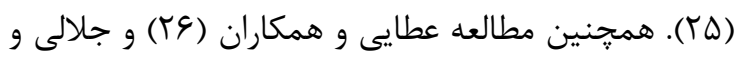

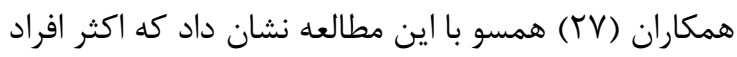

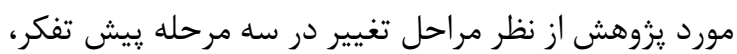

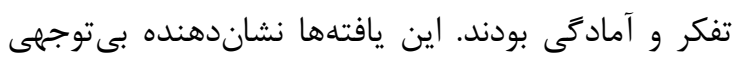

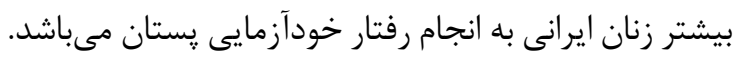

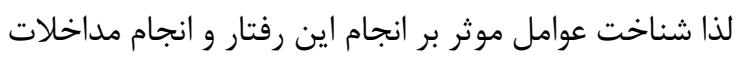

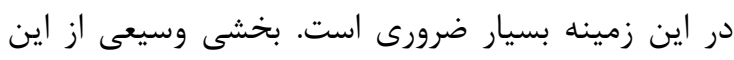

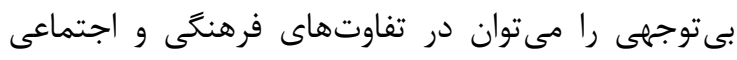

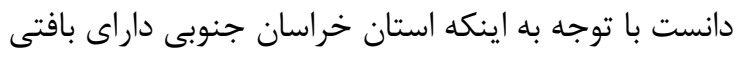
سنتى است ممكن است انجام اين كار و يا مراجعه به مراكز بهداشتى درمانى جهت يادكيرى و آموزش در اين ارئ زمينه كمتر انجام شده است و از طرفى دسترسى زنان به به مراكز

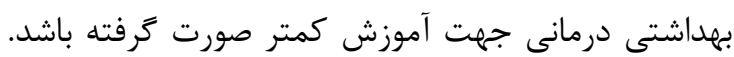

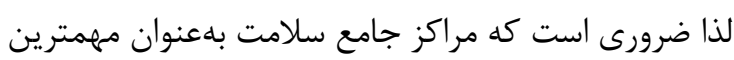

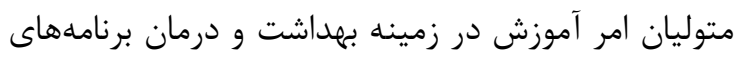

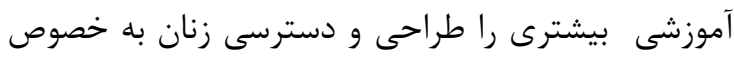

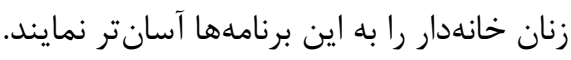
بر اساس نتايج مطالعه حاضر سطح تحصيلات وآكاهى زنان ران إنان

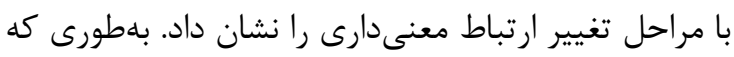

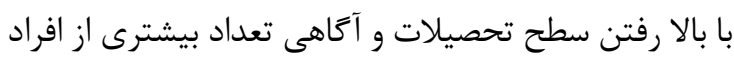

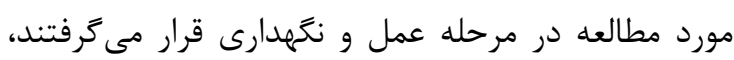
يعنى تعداد بيشترى رفتار خودآزمايى يستان را ران انجام

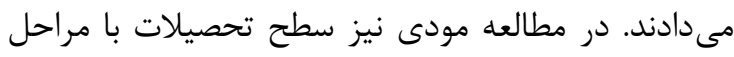

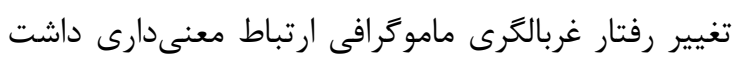

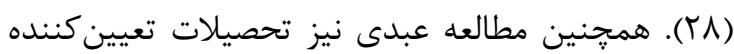
قوى در رفتار فعاليت فيزيكى بود و آنهايى كه تحصيلات

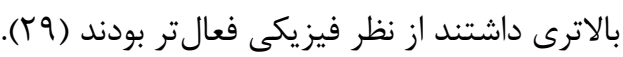

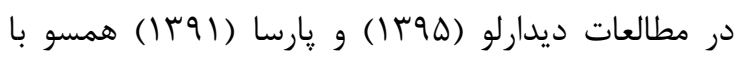

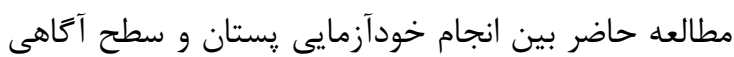




$$
\begin{aligned}
& \text { مراتب تقدير و تشكر خود را از معاونت محترم تحقيقات و }
\end{aligned}
$$

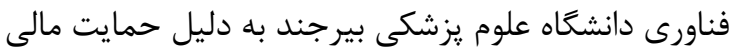

$$
\begin{aligned}
& \text { و شركت كنندگان در اين مطالعه اعلام مى دارد. } \\
& \text { تعارض منافع } \\
& \text { نويسند Fان اعلام مىدارند كه هيج تعارض منافعى در } \\
& \text { يزوهش حاضر وجود ندارد. }
\end{aligned}
$$

\section{References}

1- Ashareef B, Yaseen W, Jawa W, Barnawe Y, Alshehri W, Alqethami H, et al. Breast Cancer Awareness among Female School Teachers in Saudi Arabia: A Population Based Survey. Asian Pac J Cancer Prev. 2020; 21(2):337-42.

2- Bray F, Ferlay J, Soerjomataram I ,Siegel RL, Torre LA, Jemal A. Global cancer statistics 2018: GLOBOCAN estimates of incidence and mortality worldwide for 36 cancers in 185 countries. CA: A Cancer Journal for Clinicians. 2018; 68(6):394424.

3- Nafissi N, Khayamzadeh M, Zeinali Z, Pazooki D ,Hosseini M, EsmaeilAkbari M. Epidemiology and Histopathology of Breast Cancer in Iran versus Other Middle Eastern Countries. Middle East Journal of Cancer. 2018; 9(3):243-51.

4- Roshandel GH, Ghanbari-Motlagh A, Partovipour E, Salavati F, Hasanpour-Heidari S, Mohammadi G, et al. Cancer incidence in Iran in 2014: Results of the Iranian National Populationbased Cancer Registry. Cancer Epidemiology. 2019; 61:50-8.

5- IZ FB, Tumer A. Assessment of breast cancer risk and belief in breast cancer screening the primary healthcare nurses. J Cancer Educ. 2016; 31:575-81.

6- Naghibi A, Shojaeezade D, Montazeri A, et al. Early detection of breast cancer among women in Mazandaran, Iran. Iran J Health Sci. 2013; 1(1): 44-9.

7- Arrospide A, Rue M, Vanravesteyn NT ,et al. Evaluation of health benefits and harms of the breast cancer screening programme in the Basque Country using discrete event simulation. BMC Cancer. 2015; 15:671.

8- American Cancer Society. Recommendations for the Early Detection of Breast Cancer .2020. Available from: https://www.cancer.org

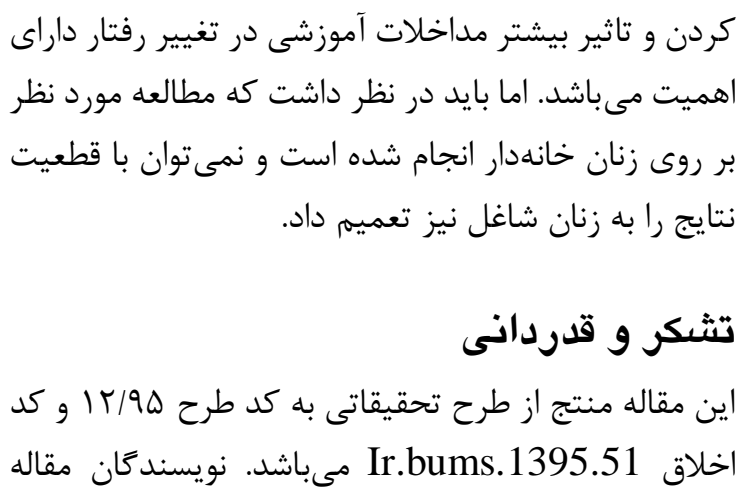

9- Tastan S, Iyigün E, Kılıc A, Unver V. Health beliefs concerningbreast self-examination of nurses in Turkey. Asian Nurs Res. 2011; 5(3): 151-6.

10-Aghamolaei T, Hasani L, Tavafian SS, Zare S. Improving breast self-examination: an educational intervention based on health belief model. Iran $\mathbf{J}$ Cancer Prev. 2011; 4(2):82-7.

11-Farshbaf-Khalili A, Shahnazi M, Vahed L, Javadi L. Status of Breast Self-Examination Performance among Women Referring to Health Centers of Tabriz, Iran. Crescent Journal of Medical and Biological Sciences. 2014; 1(3):90-6.

12-Paknejad H, saeedi V. Knowledge, attitudes and practice of breast self-examination among over 20year females in Tehran. RJMS. 2019; 25(11):3441.

13-Taleghani F, Kianpour M, Tabatabaiyan $M$. Barriers to Breast Self-examination among Iranian Women. Iranian J Nursing Midwifery Res. 2019; 24(2):108-12.

14-Shams M, Fayazbakhsh A, Saffari M. A review of studies conducted on efficacy of health educational interventions to correct women's behavior in performing breast self-examination. Basic Clin Cancer Res. 2014; 6(2):2-9.

15-Lynch L, Happell B.Implementation of clinical supervision in action: Part 2: Implementation and beyond. Int J Ment Health Nurs. 2008; 17(1):6572.

16-Glanz K, Rimer KB, Viswanath K. Health behavior and health education: theory, research, and practice. 4th ed. Jossey-Bass: San Francisco, 2008.

17-Evers KE, Paiva AL, Johnson JL, et al. Results of a transtheoretical model-based alcohol, tobacco and other drug intervention in middle schools. Addictive Behaviors. 2012; 37(9):1009-18. 
18-Moazzami Z, Soltanian AR. Correct body posture in nurses: an application of motivational interviewing. J Research Health. 2013; 3(3):46472.

19-Solhi M, L A, Taghdisi MH, Haghani H. The Effect of Trans Theoretical Model (TTM) on Exercise Behavior in Pregnant Women Referred to Dehaghan Rural Health Center in .Iranian Journal of Medical Education. 2012; 11(8):942-50.

20-Mostafavi F, Ghofranipour F, Feizi A, Pirzadeh A. Improving physical activity and metabolic syndrome indicators in women: a transtheoretical model-based intervention. International journal of preventive medicine. 2015; 6(1):28.

21-Fernandez AC, Amoyal NR, Paiva AL, Prochaska JO. Motivation for HPV Vaccination Among Young Adult Men: Validation of TTM Decisional Balance and Self-Efficacy Constructs. Am J Health Promot. 2016; 30(3):163-171.

22-Araban M, Tavafian SS, Zarandi SM, Hidarnia AR, Burri A, Montazeri A. A behavioral strategy to minimize air pollution exposure in pregnant women: a randomized controlled trial. Environmental health and preventive medicine. 2017; 22(1):26.

23-Akbari M E, Sayad S, Sayad S, Khayamzadeh M, Shojaee L, Shormeji Z, et al. Breast Cancer Status in Iran: Statistical Analysis of 3010 Cases between 1998 and 2014. International Journal of Breast Cancer.2017. 2017:2481021.

24-Vahedian Shahroodi M, Pourhaje F, Esmaily H, et al. Investigating the effectiveness of protection motivation, perceived self-Efficacy and perceived response costs by behavior of breast selfexamination. The Iranian Journal of Obstetrics, Gynecology and Infertility.2013; 15 (40): 1-9.

25-Pirasteh A, Kholdi N ,Davati A. Stages of Change and Predicting of Self Efficacy Construct in Breast Self-Examination Behavior among Women Attending at Tehran Health Centers, Iran,
2011. The Iranian Journal of Obstetrics, Gynecology and Infertility. 2013; 16(70):16-23.

26-Ataee M, ZinatMotlagh F, Aghaei A, Mohammadi MR, Mahboubi M, AhmadiJouybari $\mathrm{T}$, et al. Understanding physical activity behavior among Iranian type 2 diabetes patients: a test of the trans theoretical model change. J Biol Today's World. 2014; 3(3):53-6.

27-Jalali S, Roozbahani N, Shamsi M. Determinants of Physical Activity Behaviors among People Aged 30 to 50 Years: An Application of the TransTheoretical Model. Journal of Education and Community Health. 2019; 6(1):17-23.

28-Moodi M, Rezaeian M, Mostafavi F, Sharifirad GR. The Study of Mammography Screening Behavior Based on Stage of Change Model in Isfahanianwomen of Age 40 and Older: A Population-Based Study Journal of Advances in Medical and Biomedical Research. 2013; 21(84): 24-35.

29-Abdi J, Efthekhar H, Mahmodi M, Shojayzadeh D, Sadeghi R. Physical Activity Status of Employees of Governmental Departments in Hamadan, Iran: An Application of the Transtheoretical Model. J Health Syst Res. 2016; 12(1):50-7.

30-Didarloo A, Pourali R, Gharaaghaji R, B. R. Comparing The Effect of Three Health Education MethodsOn the Knowledge of Health Volunteers Regarding Breast Self-Examination. The Journal of Urmia Nursing and Midwifery Faculty. 2014; 12(2):109-116

31-Parsa P, Kandiah M, Parsa N. Factors Associated with Breast Self-Examination Among Malaysian Women Teachers. EastMediterr Health J. 2011; 17(6):509-16.

32-Heydari H, Sharifirad G, Kamran A. Assessment of Physical Activity Status in Patients with Type 2 Diabetes Based On Tran Theoretical Model. J Health Syst Res. 2014; 10(3):429-41. 